\title{
Serological and molecular heterogeneity among Yersinia ruckeri strains isolated from farmed Atlantic salmon Salmo salar in Chile
}

\author{
A. Bastardo ${ }^{1,2}$, H. Bohle ${ }^{3}$, C. Ravelo ${ }^{2}$, A. E. Toranzo' ${ }^{1}$, J. L. Romalde ${ }^{1, *}$ \\ ${ }^{1}$ Departamento de Microbiología y Parasitología, CIBUS, Universidad de Santiago de Compostela, 15782 Spain \\ ${ }^{2}$ Estación de Investigaciones Hidrobiológicas de Guayana, Fundación La Salle de Ciencias Naturales, 8051 Venezuela \\ ${ }^{3}$ ADL Diagnostic Chile Ltd, Puerto Montt, 5480000 Chile
}

\begin{abstract}
We investigated 11 strains of Yersinia ruckeri, the causative agent of enteric redmouth disease (ERM), that had been isolated from Atlantic salmon Salmo salar L. farmed in Chile and previously vaccinated against ERM. Phylogenetic analysis of the 16S rRNA gene sequences confirmed the identification of the salmon isolates as Y. ruckeri. A comparative analysis of the biochemical characteristics was made by means of traditional and commercial miniaturised methods. All studied isolates were motile and Tween 80 positive, and were identified as biotype 1. In addition, drug susceptibility tests determined high sensitivity to sulphamethoxazole/trimethroprim, oxytetracycline, ampicillin and enrofloxacin in all isolates. Serological assays showed the presence of O1a, O1b and O2b serotypes, with a predominance of the O1b serotype in 9 strains. Analysis of the lipopolysaccharide profiles and the correspondent immunoblot confirmed these results. Sodium dodecyl sulphate polyacrylamide gel electrophoresis (SDS-PAGE) of the outer membrane proteins revealed that all Chilean strains had profiles with a molecular weight range between 34 and $55 \mathrm{kDa}$, with 3 distinct groups based on differences in the major bands. Genotyping analyses by enterobacterial repetitive intergenic consensus (ERIC-) and repetitive extragenic palindromic (REP-)PCR techniques clearly indicated intraspecific genetic diversity among Chilean Y. ruckeri strains.
\end{abstract}

KEY WORDS: Yersinia ruckeri · Enteric redmouth disease · ERM · Atlantic salmon · Serology · Outer membrane proteins $\cdot$ Lipopolysaccharide $\cdot$ Genotyping

\section{INTRODUCTION}

Yersinia ruckeri is the causative agent of enteric redmouth (ERM) disease or yersinosis in salmonid and non-salmonid fish reared in both fresh and marine waters. Infection may result in the development of chronic or acute septicaemia with haemorrhages on the body surface and in the internal organs, and high mortalities might occur, particularly in rainbow trout Oncorhynchus mykiss (Walbaum) and Atlantic salmon Salmo salar (L.). Y. ruckeri, which was initially isolated from rainbow trout in the Hagerman Valley of Idaho, USA, in the 1950s (Rucker 1966), is now widely found in fish populations throughout North and South Amer- ica, Australia, Africa and Europe (Austin \& Austin 2007). The apparent spread of the disease throughout the different areas has been associated with the absence of strict controls and appropriate preventive programs (Horne \& Barnes 1999).

Yersinia ruckeri is a serologically variable, highly clonal species. The pathogen includes 2 biotypes. Biotype 1 strains are positive for motility and lipase activity, whereas biotype 2 strains are negative for both tests (Davies \& Frerichs 1989). The species has been grouped into 6 serovars (Stevenson \& Airdrie 1984), 5 O-serotypes (Davies 1990) or 4 O-serotypes with different subgroups (Romalde et al. 1993) by using different serotyping systems. In addition, Y. ruckeri strains 
can be grouped into clonal types on the basis of biotype, serotype and outer membrane protein (OMP) profiles (Davies 1991). Strains of serotypes O1a (classic serovar I) and O2b (classic serovar II) cause most epizootic outbreaks, and serotype O1a is predominant in cultured salmonids (Stevenson \& Airdrie 1984, Romalde et al. 1993).

ERM has been successfully controlled for decades by vaccination with monovalent killed whole cell commercial vaccines. Although formulations of most commercial vaccines are based only on serovar I (Hagerman strain), different degrees of cross-protection among serotypes have been reported (Stevenson \& Airdrie 1984). In recent years, reports of ERM vaccine breakdown have emerged in Europe and the USA, which were mostly attributed to biotype 2 strains (Austin et al. 2003, Fouz et al. 2006, Arias et al. 2007, Wheeler et al. 2009).

In Northern Europe and Chile, both of which are major production areas of farmed Atlantic salmon, the fry are routinely vaccinated with commercial rainbow trout ERM vaccines (Bravo \& Midtlyng 2007, Wheeler et al. 2009). In Chile, yersiniosis vaccines came into use in 1995 following the first occurrence of ERM in Atlantic salmon in 1992 (Toledo et al. 1993). In Chile alone, up to 140 million salmon $\mathrm{yr}^{-1}$ were vaccinated against Yersinia ruckeri between 1999 and 2003. According to the diagnostic laboratories, these vaccines have proven to be efficacious (Bravo \& Midtlyng 2007). However, during 2008 some Chilean Atlantic salmon hatcheries suffered a series of mortality episodes by ERM affecting fish previously immunised against $Y$. ruckeri.

In this study we report the full phenotypic, serological and molecular characterisation of a group of Yersinia ruckeri strains that were isolated from these ERM epizootics in Atlantic salmon farmed in Chile.

\section{MATERIALS AND METHODS}

Bacterial isolates. Several episodes of ERM with mortality up to $10 \%$ occurred in different Atlantic salmon farms in Chile during 2008. In all cases, fish had been previously immunised with an autologous vaccine based on strains of Yersinia ruckeri of both serotype O1 (Hagerman type strain) and O2b (O'Leary type strain).
Diseased fish with average weights from 2 to $60 \mathrm{~g}$ showed typical signs of ERM, such as severe haemorrhages in the mouth and eyes, and petechiae in abdominal musculature, liver, visceral fat and pyloric caeca. Bacterial isolates were aseptically collected from internal organs (liver, spleen, kidney, brain and gills). Isolates were routinely cultured and purified on tryptic soy agar (Difco Laboratories) and were kept frozen at $-80^{\circ} \mathrm{C}$ in tryptic soy broth (Difco) supplemented with $15 \%$ glycerol. The type strain of the species and representative strains of the different $\mathrm{O}$ serotypes following the scheme of Romalde et al. (1993) were also included in all analyses for comparative purposes (Table 1).

Biochemical and physiological characterisation. Bacterial isolates were biochemically characterised by conventional plate and tube tests by the procedures of Romalde et al. (1993). In addition, all cultures were identified using API 20E and API ZYM (BioMerieux) using saline solution $(\mathrm{NaCl} 0.85 \%)$ for the bacterial suspensions. The study of acid production from carbon sources was tested with API $50 \mathrm{CH}$ employing $50 \mathrm{CHB} / \mathrm{E}$ medium following the manufacturer's instructions. Strips were incubated at $25^{\circ} \mathrm{C}$, and readings were performed from 24 to $48 \mathrm{~h}$ (Romalde \& Toranzo 1991).

Table 1. Yersinia ruckeri. Strains used in this study. ${ }^{\mathrm{T}}$ : type strain. Collections are: NCIMB, National Collection of Industrial, Marine, and Food Bacteria; D. P. Anderson, National Fish Health Research Laboratory, Kearneysville, West Virginia; T. Håstein, National Veterinary Institute, Oslo; R. M. W. Stevenson, University of Guelph, Ontario; T. Cook, University of Maryland

\begin{tabular}{|lll|}
\hline Reference no. (strain) & Source & Collection \\
\hline Reference strains & & \\
NCIMB 1316 (O1a) & Oncorhynchus mykiss (USA) & NCIMB \\
NCIMB 2194 ${ }^{\mathrm{T}}$ (O1a) & O. mykiss (USA) & NCIMB \\
O-serotype strains (Romalde et al. 1993) & \\
$11.4(\mathrm{O} 1 \mathrm{a})$ & O. mykiss (Norway) & D. P. Anderson \\
$1533(\mathrm{O} 1 \mathrm{~b})$ & Salmo salar (Canada) & T. Håstein \\
RS6 (O2a) & Salvelinus fontinalis (USA) & R. M. W. Stevenson \\
$11.29(\mathrm{O} 2 \mathrm{~b})$ & O. tshawytcha (USA) & D. P. Anderson \\
RS2 (O2c) & O. mykiss (USA) & R. M. W. Stevenson \\
11.47 (O3) & O. mykiss (USA) & T. Cook \\
11.73 (O4) & O. mykiss (USA) & T. Cook \\
Fresh isolates & & \\
2550 & Salmo salar (Chile, 2008) & Laboratory collection \\
2576 & S. salar (Chile, 2008) & Laboratory collection \\
2599 & S. salar (Chile, 2008) & Laboratory collection \\
6807 & S. salar (Chile, 2008) & Laboratory collection \\
8526 & S. salar (Chile, 2008) & Laboratory collection \\
8386 & S. salar (Chile, 2008) & Laboratory collection \\
8930 & S. salar (Chile, 2008) & Laboratory collection \\
8958 & S. salar (Chile, 2008) & Laboratory collection \\
8959 & S. salar (Chile, 2008) & Laboratory collection \\
8960 & S. salar (Chile, 2008) & Laboratory collection \\
9394 & S. salar (Chile, 2008) & Laboratory collection \\
\hline
\end{tabular}


The antimicrobial susceptibility of the isolates was determined by the disc diffusion method on MuellerHinton agar (Oxoid) following the recommendations of CLSI (2009). The following chemotherapeutic agents ( $\mu \mathrm{g} \mathrm{disc}{ }^{-1} ;$ Oxoid) were used: sulphamethoxazole/ trimethoprim (25), tetracycline (30), oxytetracycline (30), ampicillin (10) and enrofloxacin (5). In parallel, the minimum inhibitory concentration (MIC) ranges of these drugs were determined using the commercial technique E-test (AB Biodisk). Since oxytetracycline is not available in this commercial test, tetracycline was employed in the E-test assays. Susceptibility to different polymyxin B concentrations ( 0.9 to $500 \mu \mathrm{g} \mathrm{ml}^{-1}$ ) was also evaluated by the disk diffusion method. In all cases, the culture density was adjusted to produce a turbidity level equivalent to that of $0.5 \mathrm{McF}$ arland standard $\left(\sim 1 \times 10^{8}\right.$ colony-forming units $\left.\mathrm{ml}^{-1}\right)$. Inhibition zone readings were performed after $48 \mathrm{~h}$ of incubation at $25^{\circ} \mathrm{C}$.

Serological characterisation. For immunological analysis, antisera raised against the reference strains of different serotypes of Yersinia ruckeri were obtained in rabbits as previously described (Romalde et al. 1993). Slide agglutination assays were carried out using whole cells and O-antigens (obtained by heating a cell suspension for $1 \mathrm{~h}$ at $100^{\circ} \mathrm{C}$ ) as described by Toranzo et al. (1987). Serological relations were further evaluated by dot blot analysis following the procedures of Cipriano et al. (1985) modified for use with a vacuum system (SNAP, Millipore) according to the manufacturer's instructions. A reaction similar to that shown by the homologous strain was recorded as positive. For these analyses, the different antisera used were previously absorbed with the heterologous strains following the procedures described by Stevenson \& Airdrie (1984). Briefly, $500 \mu \mathrm{l}$ of each serum were subjected to 3 absorption steps $\left(2 \mathrm{~h}\right.$ at $37^{\circ} \mathrm{C}$ ) with the heterologous strains (final concentration of $10^{9}$ bacteria $\mathrm{ml}^{-1}$ ), followed by an overnight incubation at $4^{\circ} \mathrm{C}$. After each incubation, bacterial cells were eliminated from the serum by centrifugation $(5000 \times g, 2 \mathrm{~min})$. Absorbed sera were maintained at $-20^{\circ} \mathrm{C}$ until use.

Lipopolysaccharide and membrane protein analysis. The preparation of lipopolysaccharide (LPS) and total and outer membrane proteins (OMP) were performed as previously described (Romalde et al. 1993). Samples were examined by sodium dodecyl sulphate polyacrylamide gel electrophoresis (SDS-PAGE; Laemmli 1970) using $12 \%$ acrylamide in the resolving gel and $4 \%$ acrylamide in the stacking gel. After electrophoresis, LPS samples were silver stained following the method of Tsai \& Frasch (1982), and protein samples were stained with $0.05 \%$ Coomassie blue R (Sigma) in 25\% propan-2-ol-10\% acetic acid. Immunoblotting of LPS components and membrane proteins was done by transferring the components separated by SDS-PAGE to nitrocellulose sheets by electrophoretic blotting following the method of Towbin et al. (1979) and treating as previously described (Romalde et al. 1993). Immunological analysis was carried out employing absorbed antisera as mentioned in 'Serological characterisation'.

16S rRNA gene analysis. Total bacterial DNA was extracted from pure bacterial cultures using the InstaGene matrix (Bio-Rad) following the manufacturer's instructions. The DNA concentration was spectrophotometrically quantified and adjusted to a concentration of $100 \mathrm{ng} \mathrm{ul}^{-1}$. Purified DNA was maintained at $-20^{\circ} \mathrm{C}$ until use. 16S rRNA gene was amplified in a temperature-gradient thermal cycler (Biometra) using the Ready-To-Go PCR beads kit (Pharmacia Biotech), and sequenced in an Automatic DNA sequencer (model 373A, Applied Biosystems) as previously described by Osorio et al. (1999). Additional sequencing was performed for type strains NCIMB $2194^{\mathrm{T}}$ and NCIMB 1316 of Yersinia ruckeri. Sequence data analysis was performed with the DNAstar Seqman program (Lasergene). Sequences of phylogenetically related species were obtained after BLAST (www.ncbi.nlm.nih.gov/ blast/) and EzTaxon (EzTaxon server 2.1, http://147.47. 212.35:8080/) searches against the latest GenBank releases. Phylogenetic trees were constructed by neighbour-joining ( $\mathrm{NJ}_{\text {; }}$ Saitou \& Nei 1987), distance matrices were calculated using Kimura's 2-parameter correction and stability of groupings, and bootstrap analysis (1000 replicates) was conducted using MEGA version 4.0 (Tamura et al. 2007), using Hafnia alvei ATCC $13337^{\mathrm{T}}$ (accession no. M59155) as the outgroup. 16S rRNA gene sequences of the Chilean isolates of $Y$. ruckeri were deposited in the GenBank database under accession numbers FN668381 to FN668391.

REP and ERIC-PCR typing. Repetitive extragenic palindromic (REP) and enterobacterial repetitive intergenic consensus (ERIC) sequences from all Yersinia ruckeri isolates were analysed as previously described (Versalovic et al. 1991). All amplifications were carried out in a temperature gradient thermal cycler (Biometra), and the PCR products were electrophoresed in agarose gels $(1.5 \% \mathrm{w} / \mathrm{v})$ with Tris-acetate-EDTA (0.004 M Tris-actate, 0.0001M EDTA, pH 8.0) electrophoresis buffer and stained with ethidium bromide $\left(2 \mu \mathrm{g} \mathrm{ml}^{-1}\right.$ ). A 50 to 2000 base pair (bp) ladder (Sigma) was used as a molecular mass marker. All gels were scanned, and images were captured by a Gel Doc-2000 gel documentation system (Bio-Rad). Patterns were analysed using the Diversity Database software (BioRad). The computed similarities among isolates were estimated by means of the Dice coefficient $\left(\mathrm{S}_{d}\right.$ i Dice 1945). Dendrograms were obtained using the unweighted pair group method average (UPGMA). 


\section{RESULTS}

\section{Biochemical and physiological characterisation}

The 11 Chilean isolates studied, which were obtained from different farms and outbreaks, exhibited great phenotypic homogeneity. All strains were Gramnegative fermentative rods, oxidase negative and positive for lysine and ornithine decarboxylase, gelatin and the Voges-Proskauer reaction, which allowed their presumptive identification as Yersinia ruckeri. Moreover, all isolates were identified as biotype 1 because of their motility and capacity to hydrolyse Tween 80 . The main differential traits among the Chilean isolates and the reference and serotype representative strains used in this study were fermentation of sorbitol, VogesProskauer reaction, hydrolysis of gelatin and utilisation of citrate (Table 2). In the API 20E test, 9 Chilean isolates showed the same numeric profile (5107100), while 2 isolates showed minor differences, rendering profiles 5307100 and 5107500 . These profiles differed from the profiles shown by the type strain NCIMB $2194^{\mathrm{T}}$, serotype representative strains 11.4 (O1a) and 1533 (O1b) (5104100), and the profile detected for RS2 (O2a), 11.29 (O2b), RS6 (O2c) and 11.47 (O3) serotype representative strains (5105500). Again, the biochemical differences were observed in Voges-Proskauer, gelatin hydrolysis, utilisation of citrate and sorbitol fermentation.

Results obtained with the miniaturised test API ZYM indicated positive activity for alkaline phosphatase, leucine arylamidase, trypsine, acid phosphatase,

Table 2. Yersinia ruckeri. Differential biochemical characteristics observed for the strains analysed. ${ }^{\mathrm{T}}$ : type strain $;+$ : positive reaction; -: negative reaction; $(\mathrm{n})$ : number of positive strains

\begin{tabular}{|c|c|c|c|c|}
\hline Test & $\begin{array}{c}\text { Voges- } \\
\text { Proskauer }\end{array}$ & Gelatin & Citrate & Sorbitol \\
\hline Chilean isolates & + & + & $+(2)^{\mathrm{a}}$ & $+(1)^{\mathrm{b}}$ \\
\hline \multicolumn{5}{|l|}{ Reference strains } \\
\hline NCMB 1316 & - & + & - & - \\
\hline \multicolumn{5}{|l|}{ O-serotype strains } \\
\hline $11.4(\mathrm{O} 1 \mathrm{a})$ & - & - & - & - \\
\hline 1533(O1b) & - & - & + & - \\
\hline RS2(O2a) & + & - & + & + \\
\hline 11.29(O2b) & - & + & + & + \\
\hline $\mathrm{RS} 6(\mathrm{O} 2 \mathrm{c})$ & + & + & - & + \\
\hline $11.47(\mathrm{O} 3)$ & + & + & + & + \\
\hline $11.73(\mathrm{O} 4)$ & - & - & - & - \\
\hline \multicolumn{5}{|c|}{$\begin{array}{l}{ }^{\text {a The }} 2 \text { positive isolates for citrate utilisation were } 8958 \\
\text { and } 8959 \\
\text { bThe positive isolate for acid production from sorbitol was } \\
6807\end{array}$} \\
\hline
\end{tabular}

$\beta$-galactosidase, $\alpha$-glucosidase and $N$-acetyl- $\beta$-glucosaminidase in all isolates studied, including reference and serotype representative strains. Moreover, the capacity to ferment glycerol, D-xylose, D-galactose, D-glucose, D-fructose, D-mannose, D-mannitol, Dacetylglucosamine, D-maltose and D-trehalose was detected in all strains by the API $50 \mathrm{CH}$ test. Only the Chilean isolate 6807 and the serotype representative strains RS2 (O2a), 11.29 (O2b), RS6 (O2c) and 11.47 (O3), were also able to ferment sorbitol.

All Chilean isolates showed a drug-susceptibility pattern similar to that of the reference strains NCIMB $2194^{\mathrm{T}}$ and NCIMB 1316, being highly susceptible to sulphamethoxazole/trimethoprim, tetracycline, oxytetracycline, ampicillin and enrofloxacin. No differences were observed between standard and E-test methods to determine the sensitivity of the Yersinia ruckeri strains studied. Moreover, Chilean isolates were sensitive to polymyxin B with a MIC of $31.2 \mu \mathrm{g} \mathrm{ml}^{-1}$, while the reference and serotype representative strains showed higher susceptibility $\left(\mathrm{MIC}=15.6 \mu \mathrm{g} \mathrm{ml}^{-1}\right.$ ).

\section{Serological characterisation}

Cross-reactions were observed for all isolates, using whole cells or thermostable O-antigens, when no absorbed antisera were employed (data not shown). Agglutination assays performed using the O-antigens and absorbed antisera revealed the presence of 3 different O-serotypes among the Chilean Yersinia ruckeri isolates examined in this study (Table 3). One isolate (2576) was identified as belonging to serotype O1 subgroup a, 9 isolates belonged to serotype O1 subgroup b, and 1 Chilean isolate (6807) reacted only with antisera against the serotype $\mathrm{O} 2$ subgroup b reference strain. The results of the dot blot test using absorbed sera support those of slide agglutination.

\section{LPS and membrane protein patterns}

Three different profiles were observed in the LPS of the Chilean Yersinia ruckeri isolates, similar to those shown by the representative strains of serotypes O1a (1 isolate), O1b (9 isolates) and O2b (1 isolate). In the patterns exhibited by the serotype O1a and O1b isolates, a minor number of bands with a greater distance among them were observed. Immunoblot assays, using absorbed antisera raised against serotype O1a, O1b and $\mathrm{O} 2 \mathrm{~b}$, supported these results (Fig. 1).

The SDS-PAGE analysis of the OMPs revealed that the isolates yielded 3 different profiles, which could be related to their serotype. One profile was observed in the reference strain NCIMB $2194^{\mathrm{T}}$ and in serotype O1a 
Table 3. Yersinia ruckeri. Serological results obtained for slide agglutination, dot blot and Western blot analysis of Chilean bacterial isolates using antisera of $Y$. ruckeri absorbed with heterologous strains. O1a, O1b, O2b: antisera raised against representative O-serotype Y. ruckeri strains 11.4, 1533 and 11.29, respectively (Romalde et al. 1993). ${ }^{\mathrm{T}}$ : type strain; LPS: lipopolysaccharide; OMP: outer membrane protein $;+$ : positive reaction; -: negative reaction

\begin{tabular}{|c|c|c|c|c|c|c|c|c|c|c|c|c|}
\hline \multirow[t]{2}{*}{ Isolate } & \multicolumn{3}{|c|}{$\begin{array}{l}\text { Slide agglutination } \\
\text { (O antigen })\end{array}$} & \multicolumn{3}{|c|}{$\begin{array}{c}\text { Dot blot } \\
\text { (O antigen) }\end{array}$} & \multicolumn{3}{|c|}{$\begin{array}{l}\text { Western blot } \\
\text { (LPS) }\end{array}$} & \multicolumn{3}{|c|}{$\begin{array}{l}\text { Western blot } \\
\text { (OMPs) }\end{array}$} \\
\hline & O1a & O1b & $\mathrm{O} 2 \mathrm{~b}$ & O1a & O1b & $\mathrm{O} 2 \mathrm{~b}$ & O1a & O1b & $\mathrm{O} 2 \mathrm{~b}$ & O1a & O1b & $\mathrm{O} 2 \mathrm{~b}$ \\
\hline 2550 & - & + & - & - & + & - & - & + & - & - & + & - \\
\hline 2576 & + & - & - & + & - & - & + & - & - & + & - & - \\
\hline 2599 & - & + & - & - & + & - & - & + & - & - & + & - \\
\hline 6807 & - & - & + & - & - & + & - & - & + & - & - & + \\
\hline 8526 & - & + & - & - & + & - & - & + & - & - & + & - \\
\hline 8386 & - & + & - & - & + & - & - & + & - & - & + & - \\
\hline 8930 & - & + & - & - & + & - & - & + & - & - & + & - \\
\hline 8958 & - & + & - & - & + & - & - & + & - & - & + & - \\
\hline 8959 & - & + & - & - & + & - & - & + & - & - & + & - \\
\hline 8960 & - & + & - & - & + & - & - & + & - & - & + & - \\
\hline 9394 & - & + & - & - & + & - & - & + & - & - & + & - \\
\hline Reference strains & & & & & & & & & & & & \\
\hline NCIMB $2194^{\mathrm{T}}$ & + & - & - & + & - & - & + & - & - & + & - & - \\
\hline NCIMB 1316 & + & - & - & + & - & - & + & - & - & + & - & - \\
\hline 11.4 & + & - & - & + & - & - & + & - & - & + & - & - \\
\hline 1533 & - & + & - & - & + & - & - & + & - & - & + & - \\
\hline 11.29 & - & - & + & - & - & + & - & - & + & - & - & + \\
\hline
\end{tabular}

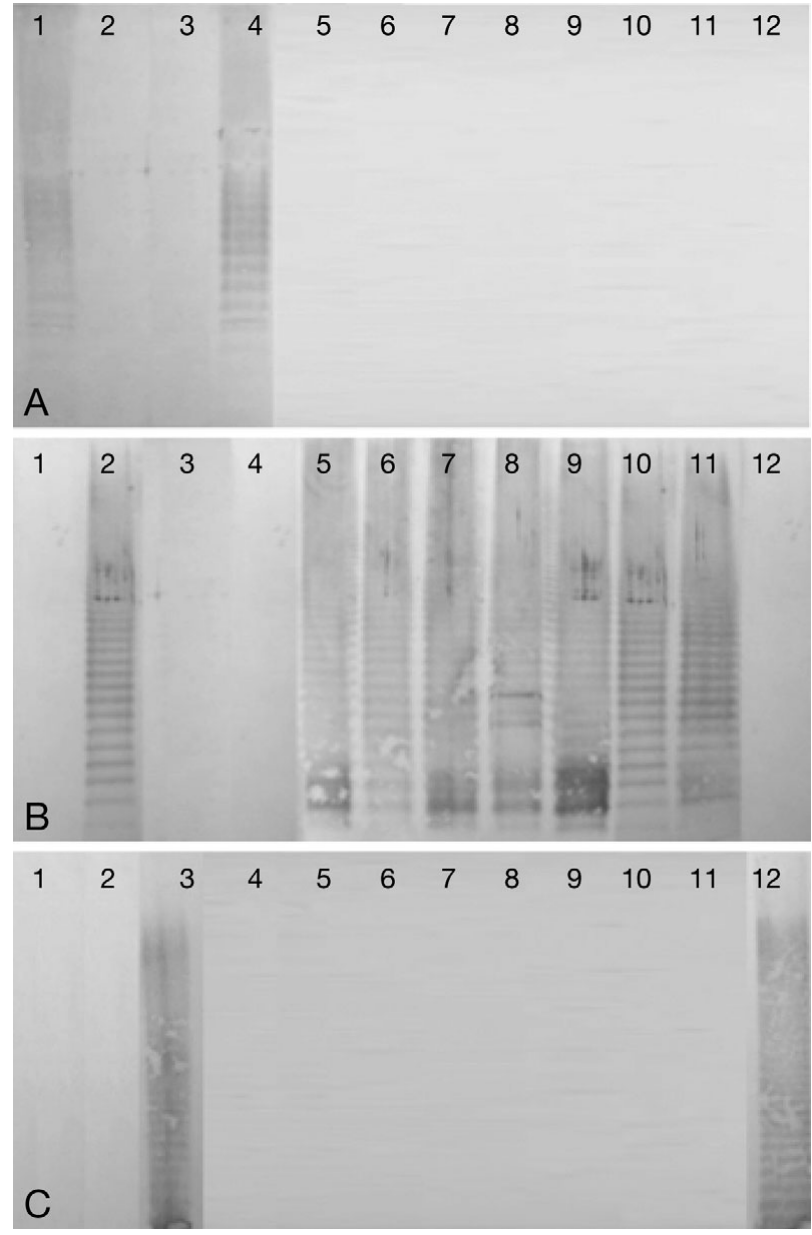

representative strain 11.4, as well as in the Chilean isolate 2576 (Fig. 2). A second OMP profile included the serotype O1b representative strain 1533 and the Chilean isolates identified as serotype O1b (Fig. 2). The representative serotype O2b strain 11.29 and the Chilean isolate 6807 yielded a third profile (Fig. 2). The Western blot assay of total and OMPs showed correspondence with the dot blot and LPS results, only when absorbed sera were used for the immunological reactions (data not shown).

\section{Genetic characterisation}

The partial 16S rRNA gene sequences of all Chilean isolates showed the highest similarity (>99.82\%) with Yersinia ruckeri NCIMB 2194 ${ }^{\mathrm{T}}$ (EF179132), followed by $Y$. kristensenii ATCC $33638^{\mathrm{T}}$ (ACCA01000078; $98.45 \%$ ) and the remaining Yersinia species (<98\%). Phylogenetic analysis grouped all Chilean isolates with the Y. ruckeri type strain, with bootstrap values of $100 \%$ (data not shown).

All Chilean Yersinia ruckeri strains were typeable, rendering discernible amplification patterns by any of

Fig. 1. Yersinia ruckeri. Immunoblot assays of the lipopolysaccharide extracted from Chilean isolates using absorbed antisera raised against (A) serotype O1a (11.4), (B) serotype O1b (1533) and (C) serotype O2b (11.29) representative strains. Lanes: $1,11.4 ; 2,1533 ; 3,11.29 ; 4,2576 ; 5,2550 ; 6,2599 ; 7$, $8526 ; 8,8930 ; 9,8959 ; 10,8960 ; 11,9394 ; 12,6807$ 


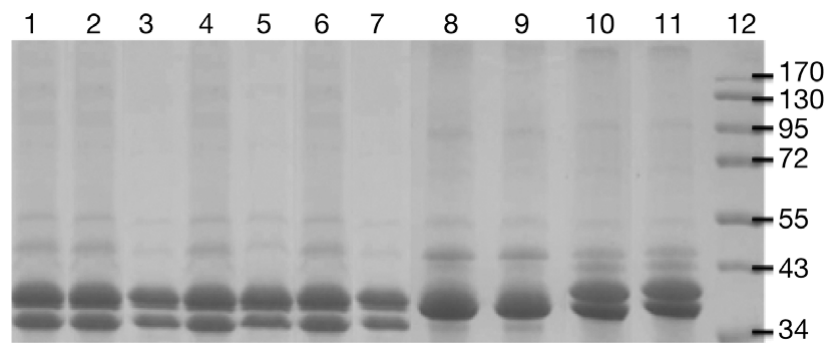

Fig. 2. Yersinia ruckeri. Outer membrane protein profiles of the strains studied. Lanes: $1,1533(\mathrm{O} 1 \mathrm{~b}) ; 2,8960 ; 3,8526 ; 4$, 9394; 5, 2550; 6, 8386; 7, 8958; 8, 11.29 (O2b); 9, 6807; 10, 11.4 (O1a); 11, 2576; 12, molecular size marker. Numbers on the right indicate the molecular size of the markers in $\mathrm{kDa}$

the PCR-based methods used. The banding patterns obtained from ERIC-PCR fingerprints showed profiles with common bands (between 8 and 10) with molecular weights from 50 to $1500 \mathrm{bp}$. Three different genetic groups were differentiated, which corresponded with the serotypes of the isolates (Fig. 3A). Cluster I grouped reference strains NCMB 1316 and serotype representative strains $11.4(\mathrm{O} 1 \mathrm{a})$ and $11.47(\mathrm{O} 3)$. Cluster II included the Chilean isolate 6807 and serotype representative strains RS2 (O2a), $11.29(\mathrm{O} 2 \mathrm{~b})$ and RS6 (O2c). Finally, Cluster III grouped the rest of the

A

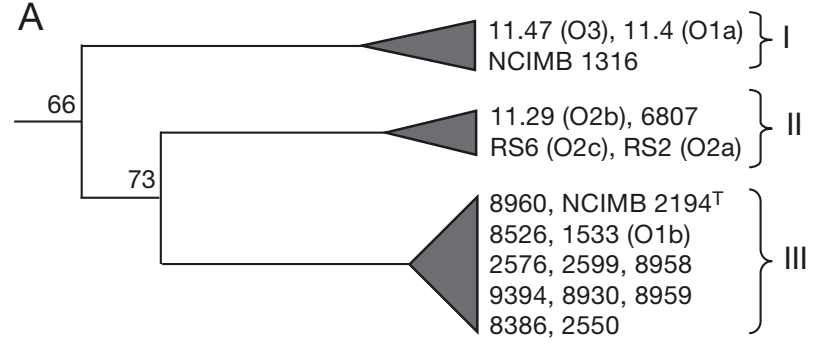

$\mathrm{B}$
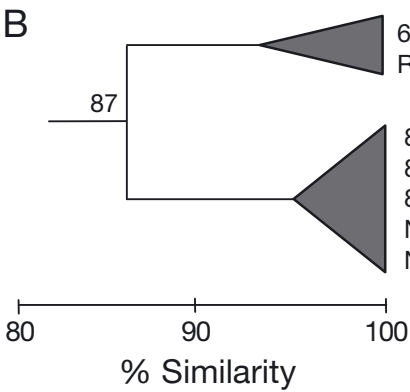

Fig. 3. Yersinia ruckeri. Clusters obtained using the Dice similarity coefficient and unweighted pair group method average (UPGMA) analysis based on (A) enterobacterial repetitive intergenic consensus (ERIC)-PCR and (B) repetitive extragenic palindromic (REP)-PCR produced patterns in $Y$. ruckeri strains
Chilean isolates with the reference strains NCIMB $2194^{\mathrm{T}}$ and the serotype representative strain 1533 (O1b). Isolates within each group showed homology in their profiles between 88 and $97 \%$. An $\mathrm{S}_{d}$ of $73 \%$ was obtained between Clusters II and III, while Cluster I joined them at $66 \%$ similarity.

Although the band profiles obtained by REP-PCR appeared to be more homogeneous, 2 patterns were detected with 9 and 11 amplification bands ranging from 150 to $2200 \mathrm{bp}$ (Fig. 3B). Cluster I grouped serotype O2 representative strains, RS2 (O2a), 11.29 (O2b) and RS6 (O2c), and also included the Chilean serotype O2b isolate (6807). Cluster II comprised the remaining Chilean isolates, the reference strain NCIMB $2194^{\mathrm{T}}$ and the serotype O1a and O1b representative strains. Within each genetic group, the strains were highly homogeneous $\left(\mathrm{S}_{d}=95-100 \%\right)$, and the similarity between Clusters I and II was $87 \%$.

\section{DISCUSSION}

Diagnosis of the causative agent of a fish disease is important to implement appropriate control strategies. Outbreaks of ERM occurred in 2008 in Chilean Atlantic salmon that had previously been vaccinated. Samples of these fish were analysed in the current study to confirm the aetiology of Yersinia ruckeri and to identify the main phenotypic and molecular characteristics of the responsible isolate.

The biochemical results showed strong homogeneity in the Chilean isolates, all of which belonged to biotype 1 (motile and lipase positive). The only variable biochemical characteristics among them were in the use of citrate and the fermentation of sorbitol. On the other hand, all Chilean isolates showed some biochemical differences to the reference strains NCMB $2194^{\mathrm{T}}$ and NCMB 1316, which were Voges-Proskauer and gelatinase positive. This variation in some biochemical tests for Yersinia ruckeri strains has been reported in other studies (Austin \& Austin 2007). Some studies reported the ability to ferment sorbitol as a distinguishing characteristic for strains of Y. ruckeri belonging to serotype O2 (Romalde et al. 2003, Austin \& Austin 2007). However, some isolates, including the different serotypes O1, O3 and O4, are also able to ferment sorbitol (Stevenson \& Airdrie 1984, Sousa et al. 2001). In this study, 1 Chilean isolate (6807) was able to ferment sorbitol and was confirmed by serological tests as belonging to serotype O2b.

The biochemical profiles obtained in the API 20E (5017100, 5307100 and 5107500), although not included in the database API system, have been previously reported for Yersinia ruckeri by other authors (Romalde \& Toranzo 1991, Austin et al. 2003). The results obtained using the miniaturised systems API 
ZYM and API $50 \mathrm{CH}$ were completely homogeneous among all isolates studied and also consistent with those obtained in conventional tests.

Although ERM mortalities in cultured salmonids have been mainly caused by strains of serotype O1a, biotype 1 (Austin \& Austin 2007), new strains of Yersinia ruckeri have been reported as causal agents in outbreaks affecting salmonids vaccinated against ERM in different geographic areas. Some of these outbreaks were attributed to emergent non-motile, Tween 80 negative, biotype 2 isolates (Austin et al. 2003, Fouz et al. 2006, Arias et al. 2007). Other cases (with lower incidence and mortality) were caused by strains of serotype O2b (Romalde et al. 2003).

The few reports available on Yersinia ruckeri in Chile described serotype O1a strains as the primary cause of outbreaks, with serotype O2 strains only occasionally detected (Troncoso et al. 1994). In contrast, the predominant serotype that we found in Chilean strains was serotype O1b (former serovar III), suggesting that commercial vaccines do not protect against this variant. The different LPS patterns exhibited by the Chilean isolates corresponded to those of serotypes O1a, O1b and O2b. Differences in the number of bands and the interband distances among serotypes are consistent with results previously reported for Y. ruckeri by other authors (Romalde et al. 1993, Sousa et al. 2001). Results of OMP analysis of the Chilean Y. ruckeri isolates supported those from previous studies (Romalde et al. 1993, Sousa et al. 2001), in which observations of distinct protein profiles were observed related to the different serotypes of Y. ruckeri.

In addition, genetic variability was observed in Chilean Yersinia ruckeri isolates using REP- and ERICPCR techniques, establishing, respectively, 2 and 3 groups related with the serotype. ERIC-PCR showed higher discriminatory power than REP-PCR, but both techniques could have some value as tools to study ERM epidemiology.

Finally, the facts that Chilean isolates in this study were associated with mortalities by ERM in salmon previously vaccinated and that they belonged to a serotype different from O1a, suggest that these emerging serotype O1b strains can represent an important pathogenic group and could explain the low efficacy of the commercial vaccines. Moreover, it is known that the massive long-term use of a single vaccine can induce a strong selective pressure, resulting in the emergence of different virulent serotypes (Bachrach et al. 2001). Further work is required to determine the in vivo biological significance of Chilean serotype O1b Yersinia ruckeri strains, including virulence studies. Such information would benefit the development of vaccines prepared with antigens from different isolates that genuinely differ in cross protectiveness.
Acknowledgements. This work was supported in part by grant AGL2006-13208-C02-01 from the Ministerio de Ciencia y Tecnología (Spain). A.B. acknowledges the FONACIT (Venezuela) for research fellowships.

\section{LITERATURE CITED}

Arias CR, Olivares-Fuster O, Hayden K (2007) First report of Yersinia ruckeri biotype 2 in the USA. J Aquat Anim Health 19:35-40

Austin B, Austin D (eds) (2007) Bacterial fish pathogens. Diseases of farmed and wild fish, 4th edn. Praxis Publishing, Chichester

Austin DA, Robertson PAW, Austin B (2003) Recovery of a new biogroup of Yersinia ruckeri from diseased rainbow trout (Oncorhynchus mykiss, Walbaum). Syst Appl Microbiol 26:127-131

Bachrach G, Zlotkin A, Hurvitz A, Evans DL, Eldar A (2001) Recovery of Streptococcus iniae from diseased fish previously vaccinated with a Streptococcus vaccine. Appl Environ Microbiol 67:3756-3758

> Bravo S, Midtlyng PJ (2007) The use of fish vaccines in the Chilean salmon industry 1999-2003. Aquaculture 270: $36-42$

Cipriano RC, Pyle JB, Starliper CE, Pyle SW (1985) Detection of Vibrio anguilarum antigen by dot blot assay. J Wildl Dis 21:211-218

CLSI (Clinical and Laboratory Standards Institute) (2009) Performance standards for antimicrobial disk susceptibility test, 10th edn. Approved Standard M02-A10. CLSI, Wayne, PA

Davies RL (1990) O-serotyping of Yersinia ruckeri with special emphasis on European isolates. Vet Microbiol 22: 299-307

> Davies RL (1991) Clonal analysis of Yersinia ruckeri based on biotypes, serotypes and outer membrane protein-types. J Fish Dis 14:221-228

> Davies RL, Frerichs GN (1989) Morphological and biochemical differences among isolates of Yersinia ruckeri obtained from wide geographical areas. J Fish Dis 12: $357-365$

> Dice LR (1945) Measures of the amount of ecological association between species. Ecology 26:297-302

> Fouz B, Zarza C, Amaro C (2006) First description of nonmotile Yersinia ruckeri serovar I strains causing disease in rainbow trout, Oncorhynchus mykiss (Walbaum), cultured in Spain. J Fish Dis 29:339-346

Horne MT, Barnes AC (1999) Enteric redmouth disease (Y. ruckeri). In: Woo PTK, Bruno DW (eds) Fish diseases and disorders, Vol 3: viral, bacterial and fungal infections. CABI Publishing, Wallingford, p 455-477

Laemmli UK (1970) Cleavage of structural protein during assembly of the head of bacteriophage T4. Nature 227: $680-685$

Osorio CR, Collins MD, Toranzo AE, Romalde JL (1999) 16S rRNA gene sequence analysis of Photobacterium damselae and nested-PCR method for rapid detection of fish pasteurellosis. Appl Environ Microbiol 65: 2942-2946

Romalde JL, Toranzo AE (1991) Evaluation of the API-20E system for the routine diagnosis of the enteric redmouth disease. Bull Eur Assoc Fish Pathol 11:147-149

Romalde JL, Margariños B, Barja JL, Toranzo AE (1993) Antigenic and molecular characterization of Yersinia ruckeri. Proposal for a new intraspecies classification. Syst Appl Microbiol 16:411-419 
Romalde JL, Planas E, Sotelo JM, Toranzo AE (2003) First description of Yersinia ruckeri serotype O2 in Spain. Bull Eur Assoc Fish Pathol 23:135-138

Rucker R (1966) Redmouth disease of rainbow trout (Salmo gairdneri). Bull Off Int Epizoot 65:825-830

Saitou N, Nei M (1987) The neighbor-joining method: a new method for reconstructing phylogenetic trees. Mol Biol Evol 4:406-425

Sousa JA, Magariños B, Eiras JC, Toranzo AE, Romalde JL (2001) Molecular characterization of Portuguese strains of Yersinia ruckeri isolated from fish culture systems. J Fish Dis 24:151-159

Stevenson RMW, Airdrie DW (1984) Serological variation among Yersinia ruckeri strains. J Fish Dis 7:247-254

Tamura K, Dudley J, Nei M, Kumar S (2007) MEGA 4: molecular evolutionary genetics analysis (MEGA) software version 4.0. Mol Biol Evol 24:1596-1599

Toledo MS, Troncoso M, Portell DP, Figueroa G (1993) Outbreak due to Yersinia ruckeri in cultured salmonids. Ann Microbiol 1:59-62

Toranzo A, Santos Y, Lemos ML, Ledo A, Bolinches J (1987)

Editorial responsibility: David Bruno,

Aberdeen, UK
Homology of Vibrio anguillarum causing epizootics in turbot, salmon and trout reared on the Atlantic coast of Spain. Aquaculture 67:41-52

Towbin H, Staehelin T, Gordon J (1979) Electrophoretic transfer of protein from polyacryalmide gel to nitrocellulose sheets: procedure and some applications. Proc Natl Acad Sci USA 76:4350-4354

Troncoso M, Toledo MS, Portell DP, Figueroa G (1994) Aislamiento de Yersinia ruckeri en salmónidos de cultivos. Av Cienc Vet 9:122-127

Tsai CM, Frasch CE (1982) A sensitive silver stain for detecting lipopolysaccharides in polyacrylamide gels. Anal Biochem 119:115-119

Versalovic J, Koeuth T, Lupski JR (1991) Distribution of repetitive DNA sequences in eubacteria and application to fingerprinting of bacterial genomes. Nucleic Acids Res 19: 6823-6831

Wheeler RW, Davies RL, Dalsgaard I, Garcia J and others (2009) Yersinia ruckeri biotype 2 isolates from mainland Europe and the UK likely represent different clonal groups. Dis Aquat Org 84:25-33

Submitted: March 25, 2010; Accepted: October 6, 2010 Proofs received from author(s): February 3, 2011 